\title{
Performance research of axisymmetric vectoring nozzle based on numerical simulations
}

\author{
Lu Chang, Eri Qitai, Yaxiong YANG
}

\author{
School of Energy and Power Engineering, Beihang University, Beijing 100191, China
}

\begin{abstract}
Keywords: axisymmetric vectoring nozzle; divergent angle; divergent wall length; numerical simulation

Abstract. A series of numerical simulations had been conducted on nozzles with different divergent geometrical parameters, and each nozzle's flow field had been simulated under different working conditions. The effects of divergent angle and divergent wall length on nozzle performance had been analyzed. The results show that, divergent wall length and divergent angle affect nozzle performance in different ways and both should be taken into account when axisymmetric vectoring nozzle performance is investigated.
\end{abstract}

\section{Introduction}

With the development of aeronautical technology, thrust vectoring nozzle has shown its advantages in many ways ${ }^{[1,2]}$. A series of investigations had been conducted to study the performance and flow characteristics of thrust vectoring nozzles ${ }^{[3-8]}$. Research results show that nozzle pressure ratios and geometric vectoring angle have significant influences on nozzles' performance. Geometrical parameters, like area ratio and divergent angle, also can affect the flow field of vectoring nozzles. In this paper, a range of axisymmetric vectoring nozzles with different divergent angles and different divergent wall lengths will be analyzed based on numerical simulations.

\section{Numerical method and verification}

Second order upwind scheme is used in the spatial discretization, and with second implicit scheme adopted for the time. The turbulent model is RNG $k-\varepsilon$ model, and standard wall function is adopted for wall treatment. The base geometry of thrust vectoring nozzle is shown in Fig.1. The diameter of nozzle throat is $0.05756 \mathrm{~m}$, the length of nozzle divergent section is $0.050784 \mathrm{~m}$, the area ratio is 1.35 and the designed nozzle pressure ratio is 5.01. The computational field is shown in Fig.2, which boundary conditions include: nozzle inflow total temperature is $300 \mathrm{~K}$, nozzle pressure ratios are $0.4 \mathrm{NPR}_{\mathrm{D}}, 1.4 \mathrm{NPR}_{\mathrm{D}}, 1.6 \mathrm{NPR}$ for different working conditions, flight Mach number is 0 and pressure of outflow is standard atmospheric pressure.

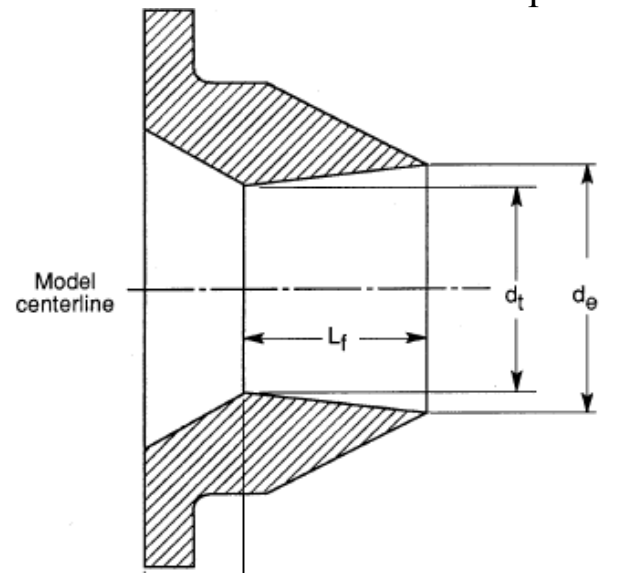

Fig.1 Figure of the nozzle

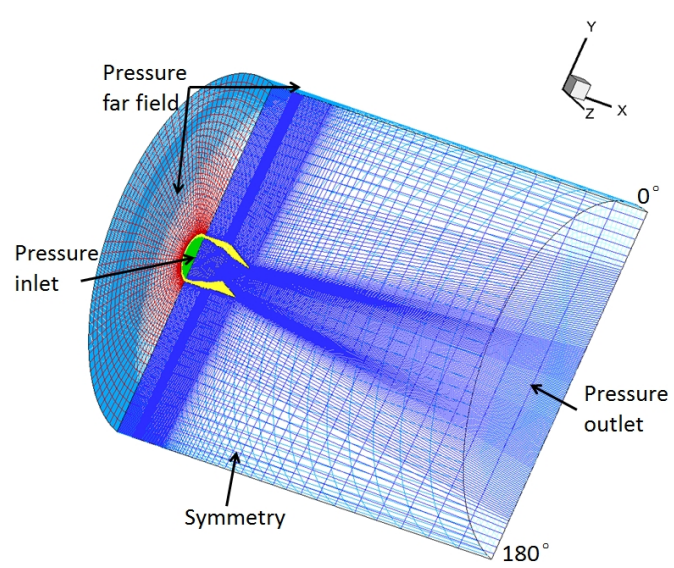

Fig.2 Mesh of the computation field

The pressure distributions of nozzles with different NPRs are shown in Fig.3. The performances calculated from simulations and experiments are compared in Table 1. It can be found that the method used in these simulations can be used in following studies. 
Table 1 Comparisons of nozzle performances

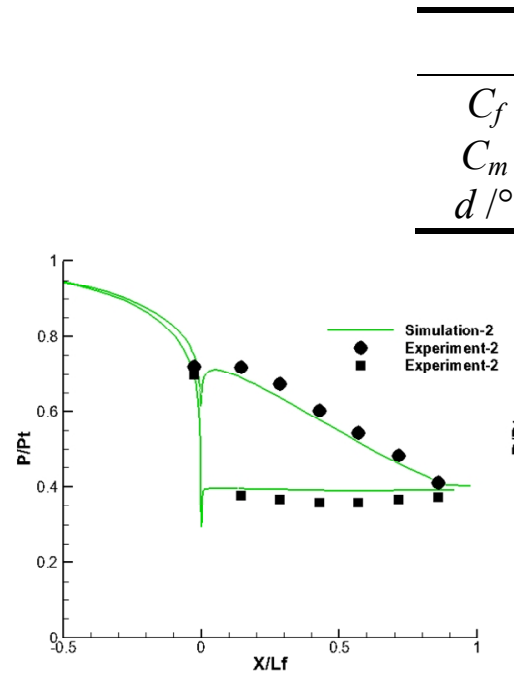

(a) $0.4 \mathrm{NPR}_{\mathrm{D}}$

\begin{tabular}{cccc} 
& Experiment & CFD & $\triangle$ \\
\hline$C_{f}$ & 0.9811 & 0.9746 & $0.66 \%$
\end{tabular}

$C_{m} \quad 0.9196 \quad 0.9298 \quad 1.10 \%$

Fig.3 Comparisons of pressure distribution of nozzle with different NPRs

\section{Results and discussions}

All results shown in this paper are get from nozzles working at $1.6 \mathrm{NPR}_{\mathrm{D}}$, thrust vectoring angle is $10^{\circ}$.

The contours of Mach number of nozzles with divergent angle $\beta=2^{\circ}$ are shown in Fig $4(\mathrm{a}) \sim(\mathrm{c})$. The divergent lengths of nozzles are $L_{f} / d_{t}=0.88, L_{f} / d_{t}=1.32, L_{f} / d_{t}=1.80$, respectively. Fig.5 shows pressure distributions of nozzles with different divergent lengths.

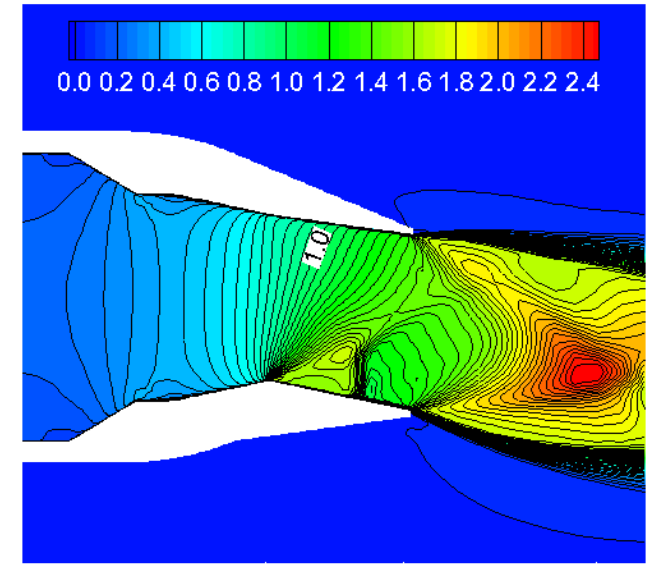

(a) $\beta=2^{\circ}, L_{f} / d_{t}=0.88$

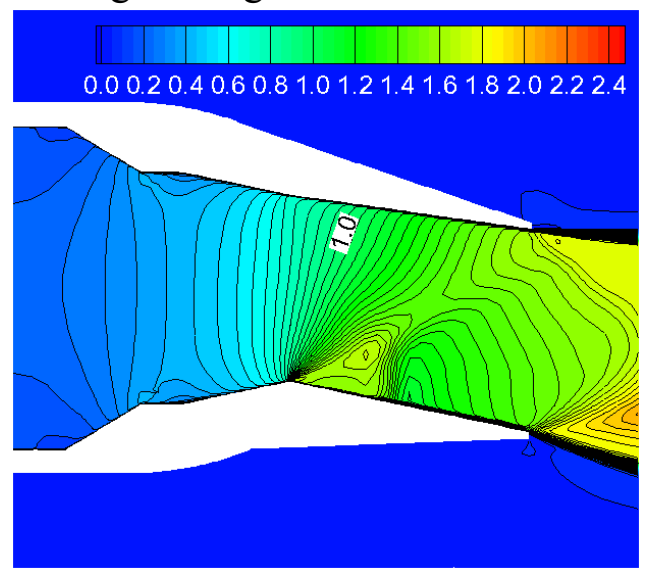

(b) $\beta=2^{\circ}, L_{f} / d_{t}=1.32$

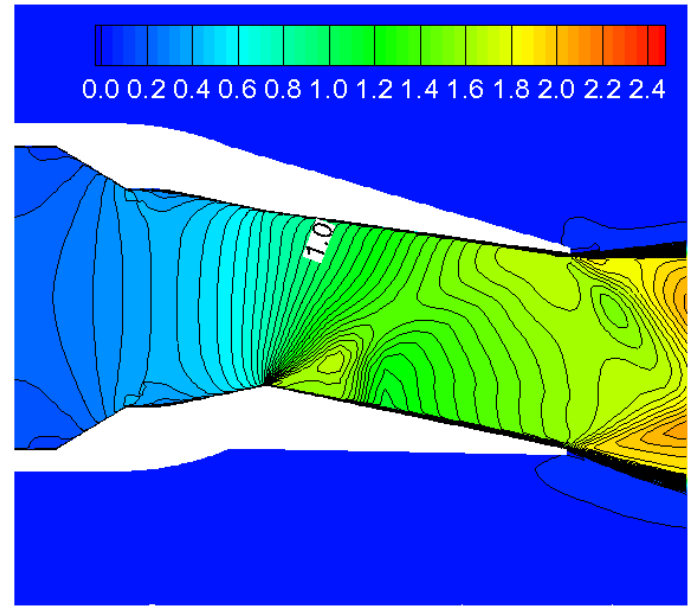

(c) $\beta=2^{\circ}, L_{f} / d_{t}=1.80$

Fig.4 Contours of Ma of nozzles with different divergent wall lengths 
The divergent angles of divergent walls change when the nozzle is in vectoring condition, which makes over-expanded flow and under-expanded flow both exist in nozzle flow field.

The flow field of nozzles with different divergent wall lengths are similar near the up wall, the pressure distributions also coincide near the wall. There are shock waves near the low walls, which caused by over-expanded flow. Since the locations of the shock waves are similar, the effect of low pressure on normal force increases and the effective vectoring angle decreases as the wall length elongate, which bring out the figure shown in Fig.6.

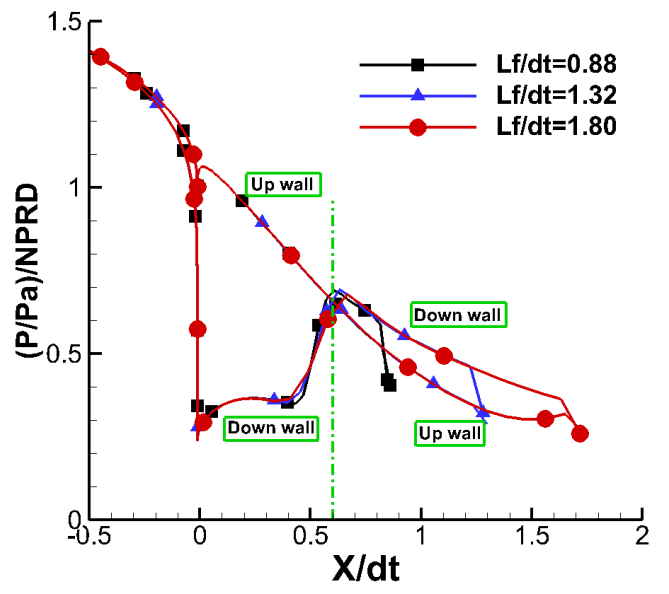

Fig.5 Pressure distributions of nozzles with different divergent wall lengths

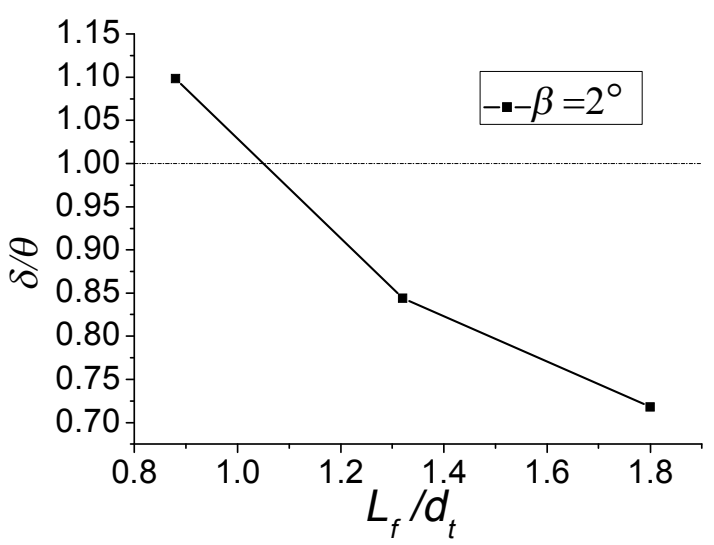

Fig.6 Effective thrust vector versus divergent wall length

The contours of pressure distributions of nozzles with divergent wall length $L_{f} / d_{t}=1.80$ are shown in Fig 7(a) (c). The divergent angles of nozzles are $\beta=2^{\circ}, \beta=5.26^{\circ}, \beta=10^{\circ}$, respectively.

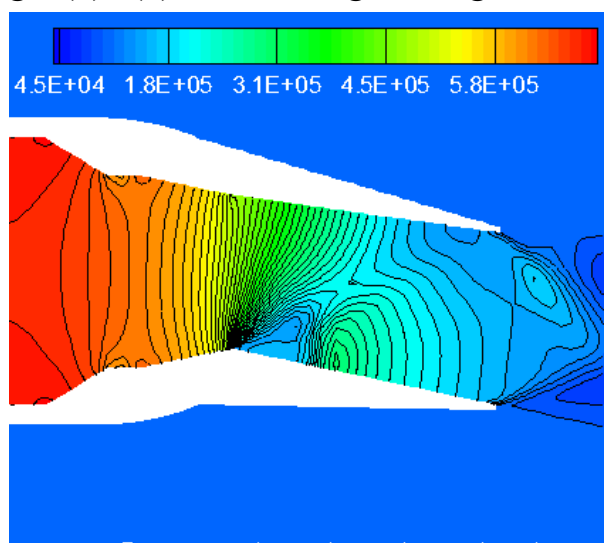

$(\alpha) \beta=2^{\circ}, L_{f} / d_{t}=1.80$

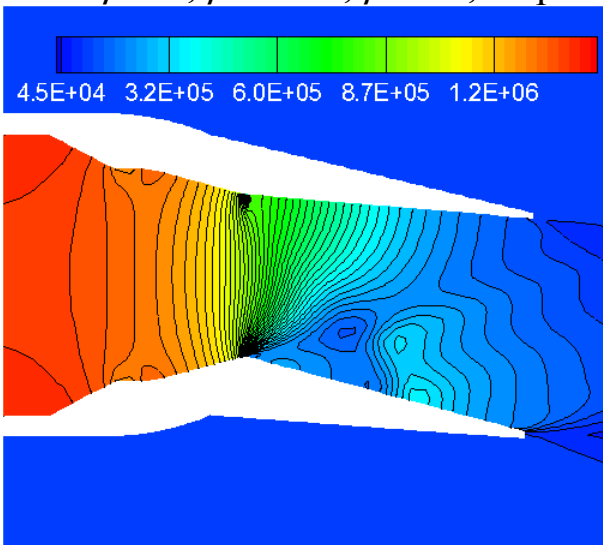

(b) $\beta=5.26^{\circ}, L_{f} / d_{t}=1.80$

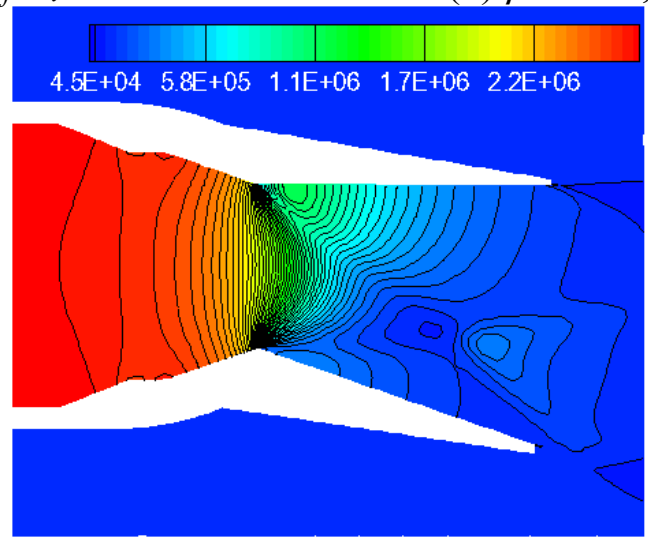

(c) $\beta=10^{\circ}, L_{f} / d_{t}=1.80$

Fig 7 Contours of static pressure of nozzles with different divergent angle

Shock waves show in nozzle flow field when $\beta=2^{\circ}$ and $\beta=5.26^{\circ}$, however, there is no shock wave in nozzle with $\beta=10^{\circ}$. The reasons for this phenomena is that nozzles with different divergent 
angles have different changes when nozzles vectored. For example, the vectoring angle of first nozzle's up wall is $9.9^{\circ}$, the vectoring angle of second nozzle's up wall is $9.76^{\circ}$. For this reason, flows near the low walls have different over-expanded conditions and different low pressure areas, which bring out the figure shown in Fig.8.

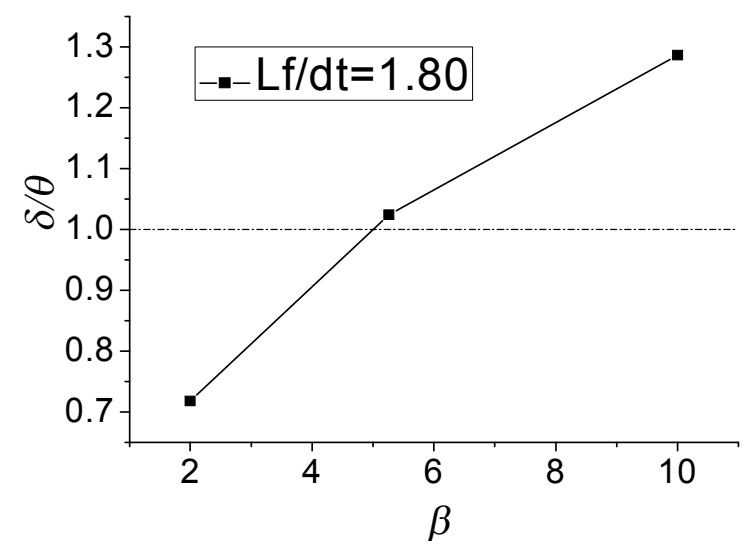

Fig. 8 Effective thrust vector versus divergent angle

\section{Summary}

Axisymmetric vectoring nozzles with varies divergent parameters in vectoring working conditions have been studied based on 3D numerical simulations. The results show that:

1)Divergent wall length and divergent angle both have significant influences on nozzles flow field.

2)Under the same working conditions, nozzles with smaller divergent angles tend to not having shock waves. For this reason, there are smaller low pressure areas and bigger effective vectoring angles.

3)Under the same working conditions, nozzles with different divergent wall lengths have varies sized low pressure area, which affect normal force and effective vectoring angles.

4)Both divergent wall length and divergent angle should be taken into account when axisymmetric vectoring nozzle performance is investigated.

\section{References}

[1] John S. Orme, Ross Hatha way, Michael D. Ferguson. Initial flight test evaluation of the F-15 active axisymmetric vectoring nozzle performance [R]. AIAA 1998-3871.

[2] Erich A. Wilson, Dan Adler, Benjamin Z.Bal-Or, et al.Optimizing subcritical-flow thrust-vectoring of converging-diverging nozzles [J].Journal of Propulsion and Power, 2000, 16(3):202-206.

[3] George T. Carson, Jr., Francis J. Capone. Static internal performance of an axisymmetric nozzle with multiaxis thrust-vectoring capability[J]. NASA TM, 4237, 1991.

[4] A. Matesanz, A. Velazquez, M. Rodriguez. Performance analysis of an axisymmetric thrust-vectoring nozzle by using the FUNSIF3D code[J]. AIAA-95-2743.

[5] John S. Orme, Robert L.Sims. Selected performance measurement of the F-15 active axisymmetric thrust-vectoring nozzle[R]. AIAA-1999.

[6] Erich A. Wilson, Dan Adler, Pinhas Z. Bar-Yoseph. Geometric evaluation of axisymmetric thrust-vectoring nozzles for aerodynamic performance predictions[J]. .Journal of Propulsion and Power, 2002, 18(3):712-716. 
[7] Erich A. Wilson, Dan Adler, Pinhas Z. Bar-Yoseph. Nozzle performance modeling[J]. AIAA Journal, 2002, 40(7):1331-1338.

[8] Erich A. Wilson, Dan Adler, Pinhas Z. Bar-Yoseph. Thrust-vectoring nozzleperformance modeling[J]. Journal of Propulsion and Power, 2003, 19(1):39-47. 